\title{
The Association of Subacute Thyroiditis with COVID-19: a Systematic Review
}

\author{
Muhammad Aemaz Ur Rehman ${ }^{1}$ (D) Hareem Farooq ${ }^{1}$ (D) Muhammad Mohsin Ali $^{2}$ (D) \\ Muhammad Ebaad Ur Rehman ${ }^{3}$ (D) $\cdot$ Qudsia Anwar Dar ${ }^{4}$. Awab Hussain ${ }^{1}$ (if
}

Accepted: 13 April 2021 / Published online: 29 April 2021

(C) Springer Nature Switzerland AG 2021

\begin{abstract}
The multisystem effects of SARS-CoV-2 encompass the thyroid gland as well. Emerging evidence suggests that SARS-CoV-2 can act as a trigger for subacute thyroiditis (SAT). We conducted a systematic literature search using PubMed/Medline and Google Scholar to identify cases of subacute thyroiditis associated with COVID-19 and evaluated patient-level demographics, major clinical features, laboratory findings and outcomes. In the 21 cases that we reviewed, the mean age of patients was $40.0 \pm$ 11.3 years with a greater female preponderance $(71.4 \%)$. Mean number days between the start of COVID-19 illness and the appearance of SAT symptoms were $25.2 \pm 10.1$. Five patients were confirmed to have ongoing COVID-19, whereas the infection had resolved in 16 patients before onset of SAT symptoms. Fever and neck pain were the most common presenting complaints $(81 \%)$. Ninety-four percent of patients reported some type of hyperthyroid symptoms, while the labs in all 21 patients $(100 \%)$ confirmed this with low TSH and high T3 or T4. Inflammatory markers were elevated in all cases that reported ESR and CRP. All 21 cases $(100 \%)$ had ultrasound findings suggestive of SAT. Steroids and anti-inflammatory drugs were the mainstay of treatment, and all patients reported resolution of symptoms; however, 5 patients $(23.8 \%)$ were reported to have a hypothyroid illness on follow-up. Large-scale studies are needed for a better understanding of the underlying pathogenic mechanisms, but current evidence suggests that clinicians need to recognize the possibility of SAT both in ongoing and resolved COVID-19 infection to optimize patient care.
\end{abstract}

Keywords COVID-19 · SARS-CoV-2 · Subacute thyroiditis · De Quervain's thyroiditis · Viral thyroiditis

\section{Introduction}

Subacute thyroiditis (also called as De Quervain's thyroiditis, viral thyroiditis, subacute granulomatous thyroiditis, or giant cell thyroiditis) is a self-limiting inflammatory disorder of the thyroid gland which usually follows or coexists with a viral

This article is part of the Topical Collection on Covid-19

Muhammad Aemaz Ur Rehman

aemaz100@gmail.com

Hareem Farooq

hareemfarooq29@gmail.com

Muhammad Mohsin Ali

mohsinali@kemu.edu.pk

Muhammad Ebaad Ur Rehman

ebaadcr7@outlook.com

Qudsia Anwar Dar

qudsiaabbas@gmail.com infection [1]. The etiology of SAT has been linked to viral infections such as mumps, measles, rubella, coxsackie, and adenovirus, either through direct viral toxicity or inflammatory response against the virus $[2,3]$. It generally presents in women with neck or jaw pain, tender thyroid gland, and systemic signs/symptoms [2]. As of February 3, 2021, WHO on

Awab Hussain

awabhussain12@gmail.com

1 King Edward Medical University, Lahore 54000, Pakistan

2 Department of Critical Care, Kaul Associates, Doctors Hospital And Medical Centre, Lahore, Pakistan

3 Allama Iqbal Medical College, Lahore, Pakistan

4 Department of Ophthalmology, King Edward Medical University/ Mayo Hospital, Lahore 54000, Pakistan 
its official website has reported more than 103 million documented cases of COVID-19 while the death toll is above 2.2 million. Efforts are being made to identify the endocrinological effects of COVID-19, and abnormalities of hypothalamicpituitary-thyroid (HPT) axis have been reported [4]. The interplay between thyroid hormones and immune system along with the direct cytotoxic effect of the virus is proposed to play a role in these abnormalities, including subacute thyroiditis [4]. The increasing evidence of SAT during or after the COVID-19 infection has been reported in various published cases [5-17], which highlights the concern that physicians ought to consider COVID-19 (ongoing or previous) as an etiological factor/trigger in patients presenting with subacute thyroiditis. This is especially important amidst the ongoing pandemic or even in the future as physicians encounter SARS-CoV-2. All these factors, coupled with lack of a published systematic review on this topic, encouraged us to undertake this write-up.

\section{Methods}

\section{Search Strategy}

Online databases including PubMed/Medline and Google Scholar were searched for articles published until February 3, 2021. Search strategy followed Preferred Reporting Items for Systematic Reviews and Meta-Analyses (PRISMA) guidelines by using keywords like the following: COVID-19, SARS-CoV-2, Subacute Thyroiditis, De Quervain's Thyroiditis, and Viral Thyroiditis. All studies, regardless of time, language, and country of publication, and all types of research articles were scrutinized. The bibliographies of individual case reports and case series were also scrutinized to find any relevant cases. The final available references were downloaded into an EndNote library. The complete strategy is outlined in the PRISMA flowchart (Fig. 1).

\section{Study Selection}

The relevant published articles on this topic were mainly case reports and case series. Joanna Briggs Institute Critical Appraisal Tool [18] was employed by two authors independently to assess the quality of all case reports and case series. Both the authors engaged in discourse to reach one consensus score for each article. One case report was translated from Portuguese into English via Google Translator, but it was excluded due to a poor score on Critical Appraisal. All the other case reports and case series included in the final analysis were in English language. Data were curated and organized in the form of two tables each for case reports and case series. One table focused on patient demographics, clinical features, treatment(s), and follow-up/outcome. The other table focused on lab investigations and imaging results. Continuous
Fig. 1 PRISMA flow diagram

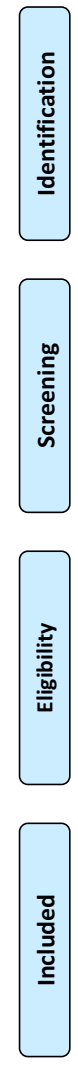

Records identified through Google Scholar $(n=18)$ and Pubmed $(n=12)$ search
Additional records identified through bibliographies $(n=05)$
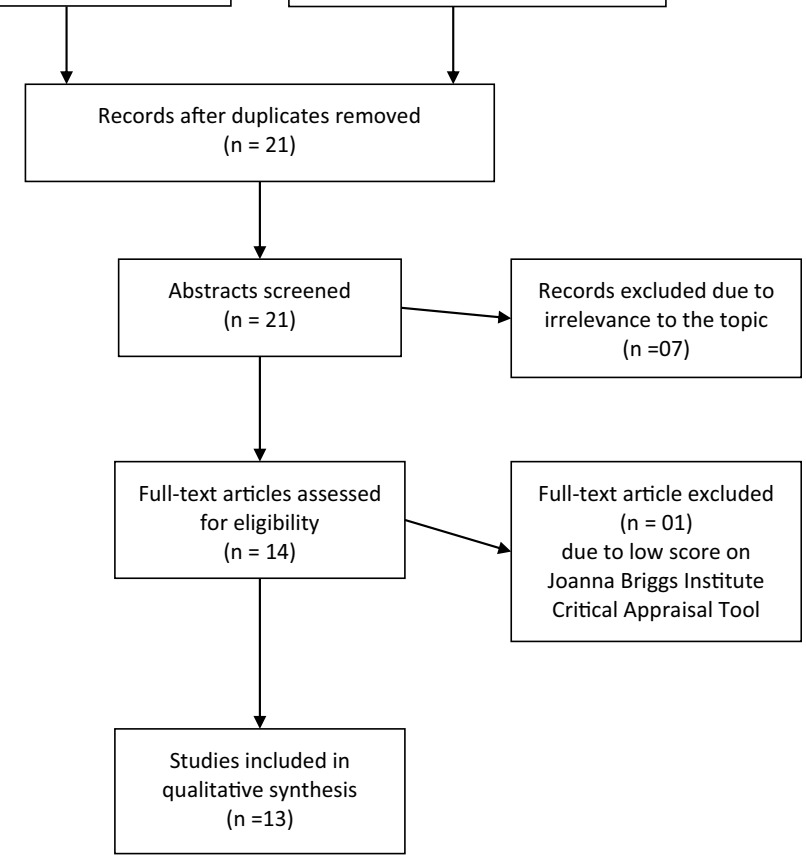


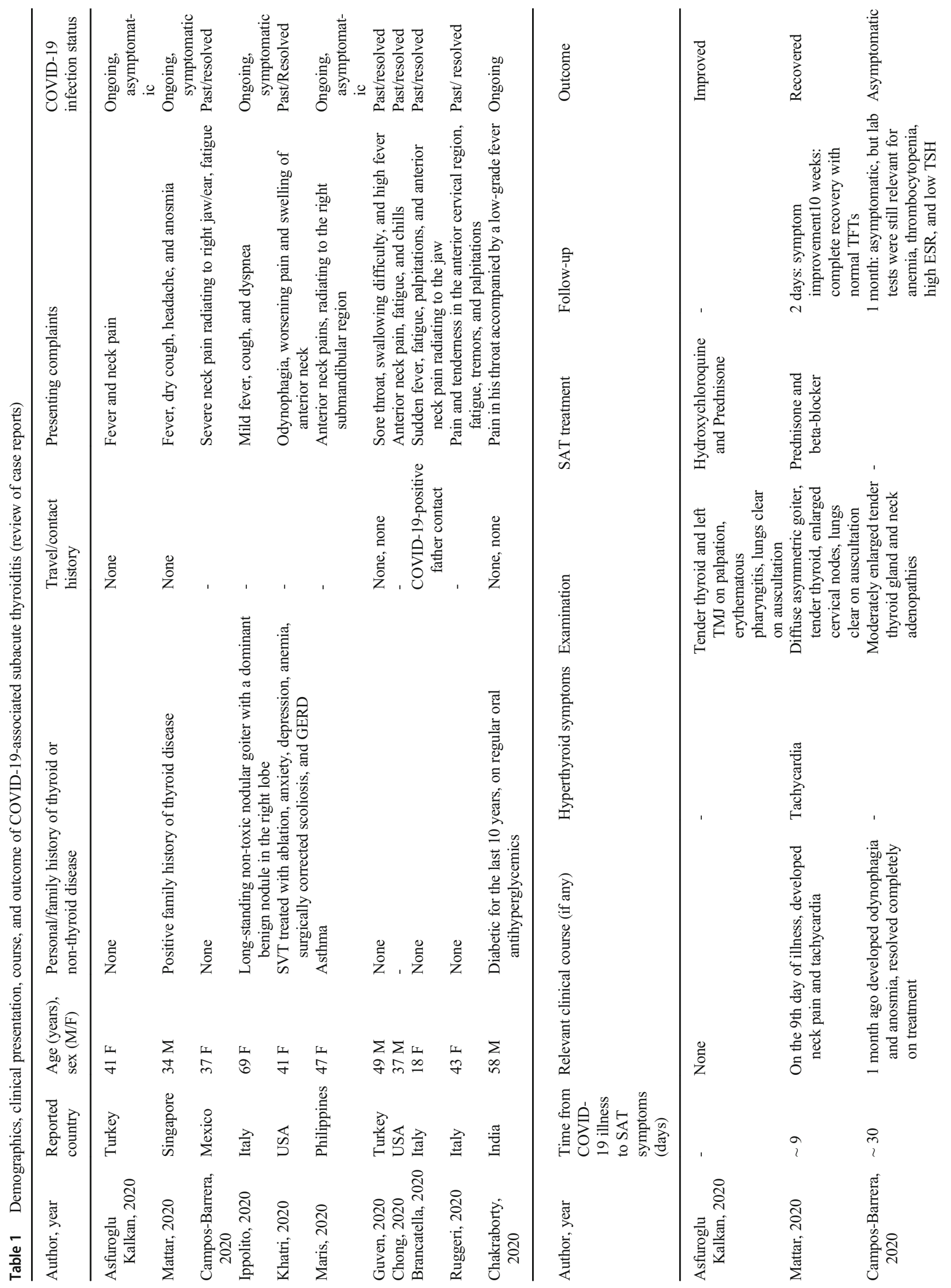




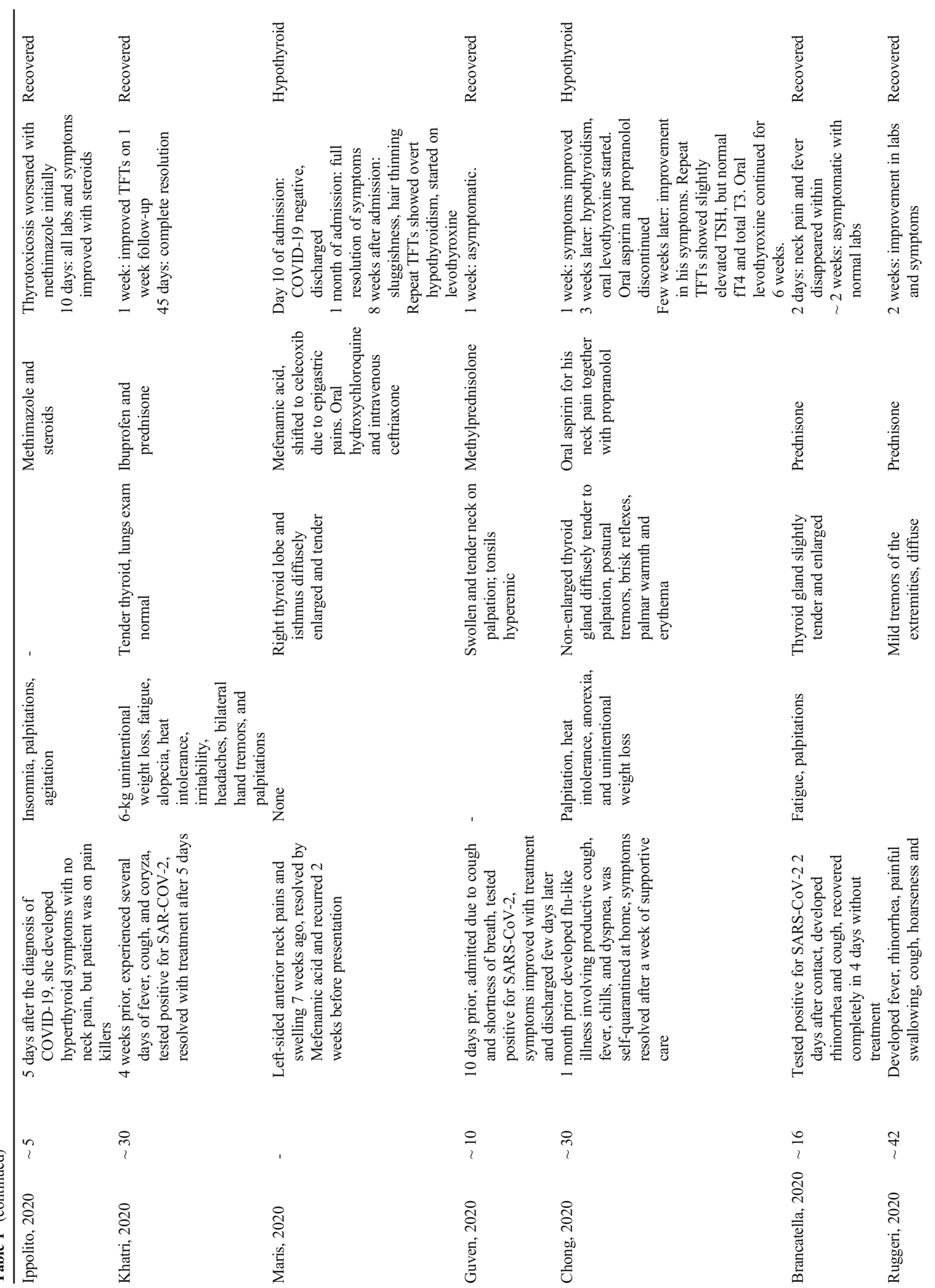


variables were presented as means \pm standard deviations, and categorical variables were presented as absolute values and percentages. Microsoft Excel was used for data extraction and statistical analysis for this study.

\section{Results}

Our search identified 30 articles; 9 were excluded due to duplication, and 7 articles on COVID-19 were excluded because they did not address subacute thyroiditis and 1 was excluded because it scored low on Critical Appraisal. Finally, 13 articles - 11 case reports and 2 case series [5-17] - were included in the final analysis. Since 10 patients were described in the two case series, individual data from 21 total patients is described here, in the form of 2 tables each for case reports (Tables 1 and 3) and case series (Tables 2 and 4). The mean age of patients was $40.0 \pm 11.3$ years (range $18-69$ years). Out of the 21 patients, 15 were females $(71.4 \%)$ and 6 were males (28.6\%). Most cases were reported in Italy $(n=7 ; 33.3 \%)$ and Iran $(n=6 ; 28.6 \%), 2$ in the USA $(9.5 \%)$ and Turkey $(9.5 \%)$ each. One case $(4.8 \%)$ each was reported in Singapore, Mexico, the Philippines, and India. Out of the 21, 9 reported a contact/travel history (42.9\%), 4 reported no contact history, whereas the remaining studies did not mention whether or not exposure had occurred. Only 2 reports mentioned a comorbidity, with one patient having long-standing diabetes, and 1 having asthma. One patient had a family history of thyroid disease, whereas 2 patients had a goiter long before the onset of any symptoms.

Mean days between the start of COVID-19 illness and the appearance of SAT symptoms were $25.2 \pm 10.1$ (minimum 5 days and maximum 42 days). Five patients had ongoing COVID-19, whereas the infection had resolved in 16 patients before onset of SAT symptoms. COVID-19 diagnosis was made by RT-PCR swabs in 12 patients $(57.1 \%)$, whereas in 9 cases (42.9\%) with no current symptoms, no previous RTPCR, or a negative current RT-PCR, a past COVID-19 illness was confirmed by the presence of IgG/IgM against SARCOV2 in the patients' blood. Out of the 13 people who had a chest X-ray/CT chest at presentation for SAT, only 3 showed abnormalities (21.3\%).

Fever and neck pain were the most common presenting complaints with each being present in 17 out of 21 patients $(81 \%)$. Other complaints included fatigue, palpitations, odynophagia, sweating, and throat pain. Out of the 16 reports that mentioned neck examination, a tender thyroid was found in all 16 patients (100\%). Out of the 21 patients, 17 mentioned (94.4\%) the presence of hyperthyroid symptoms like fatigue and palpitations, 1 mentioned absence of such symptoms, and 3 reports did not mention anything in this regard. Out of the 21, 15 cases reported ESR (erythrocyte sedimentation rate) values which were high in all 15 patients $(100 \%)$, with a mean 


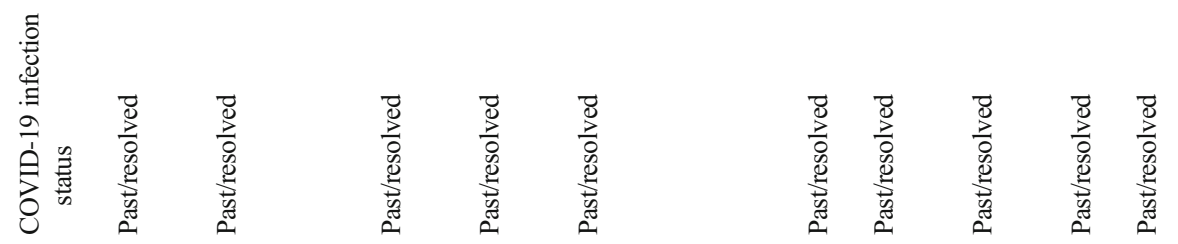

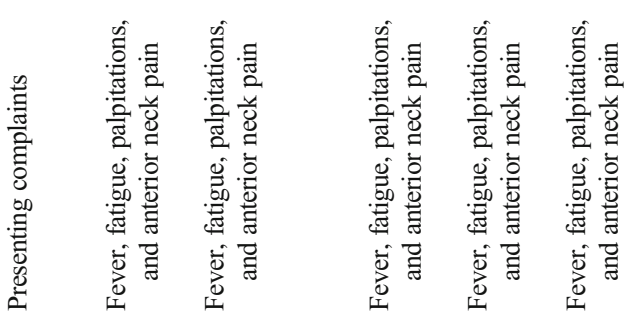
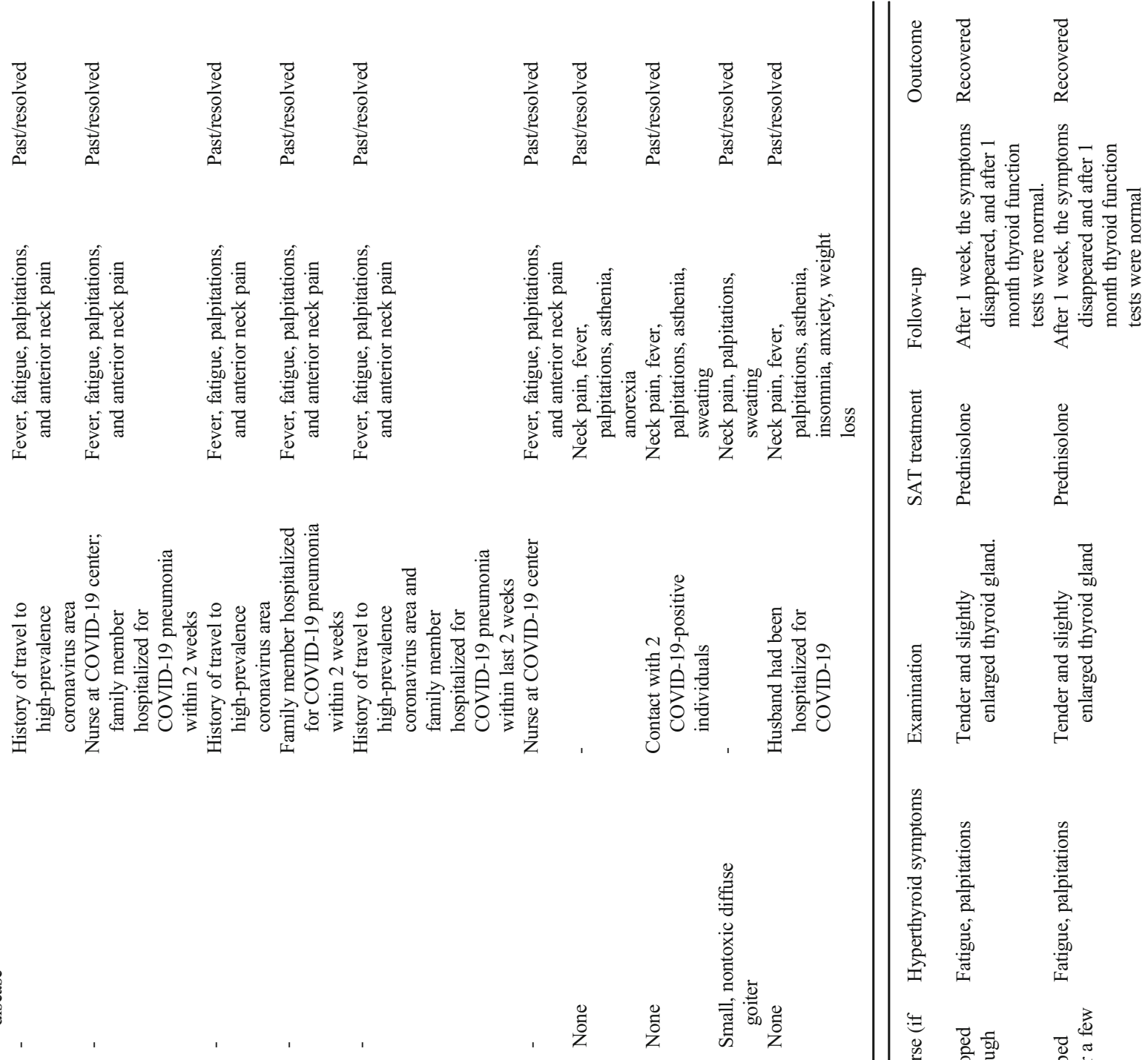

部焉

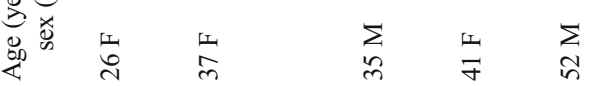

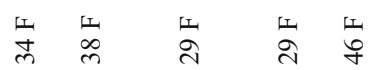

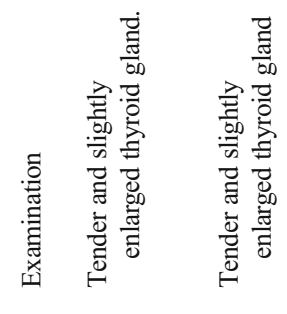

(1)

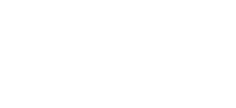

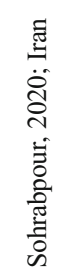

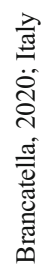

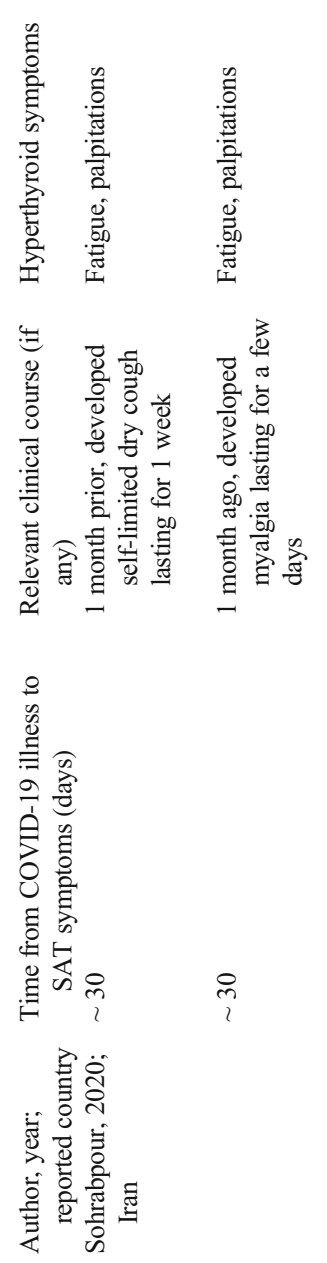




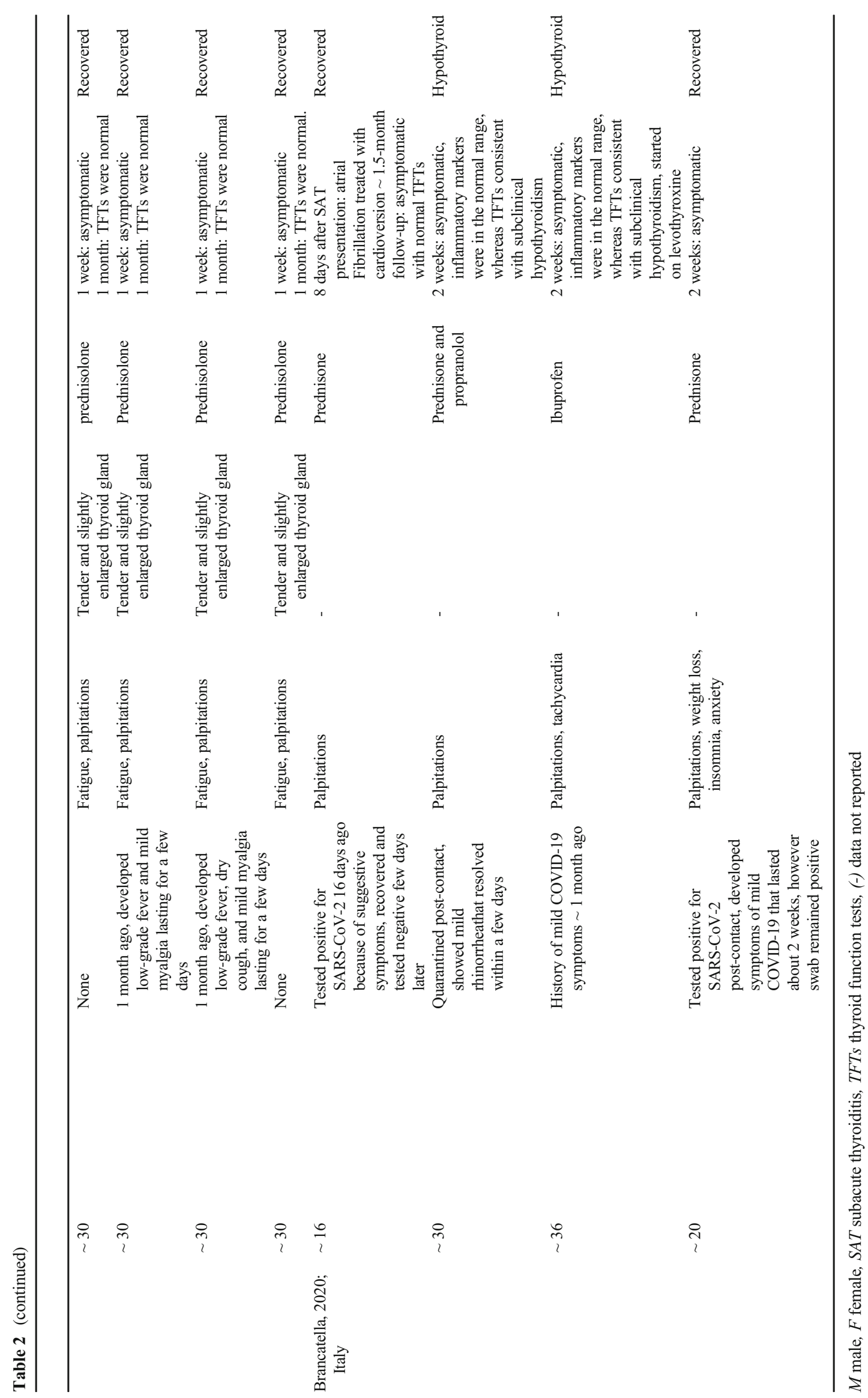




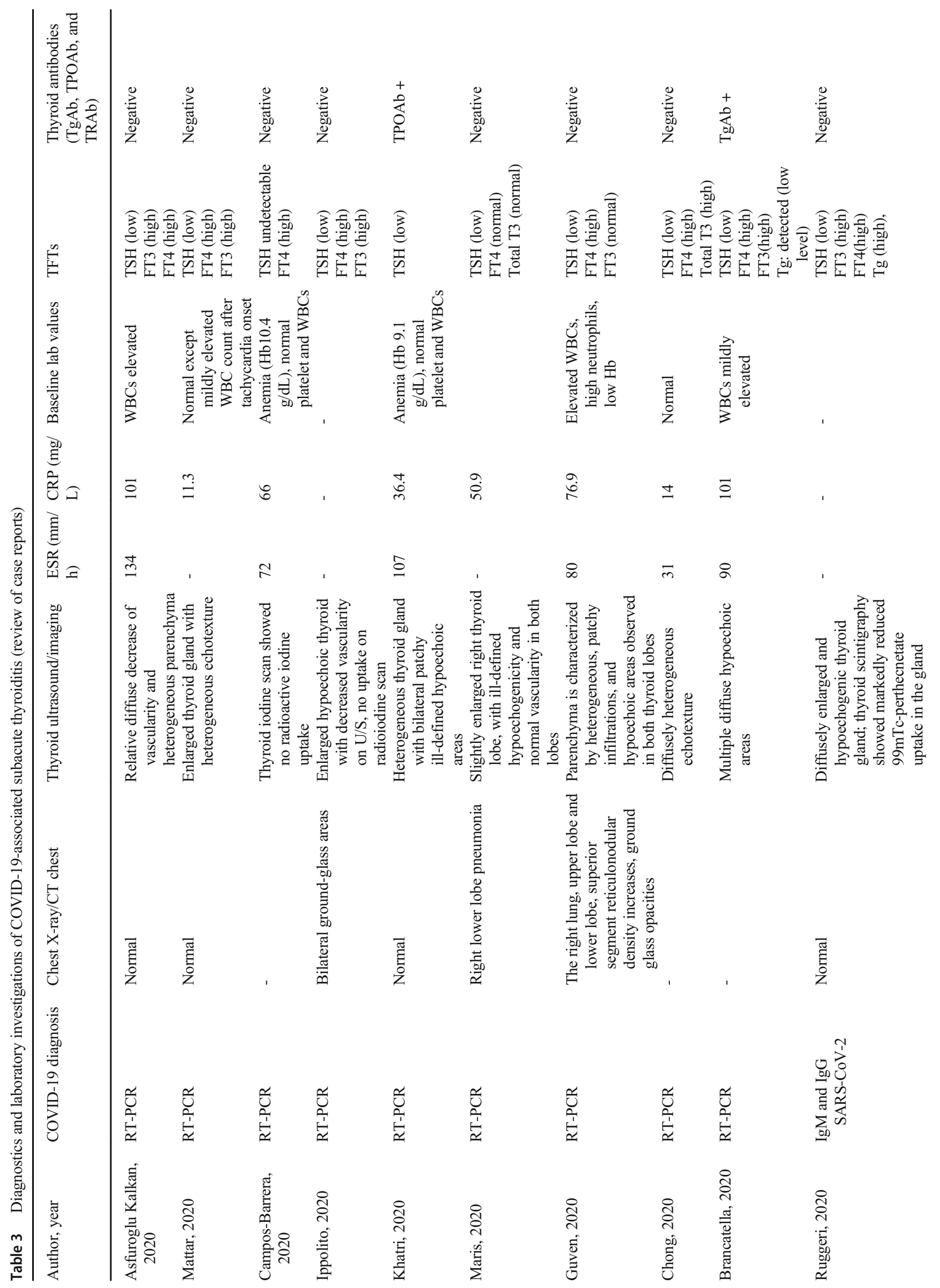




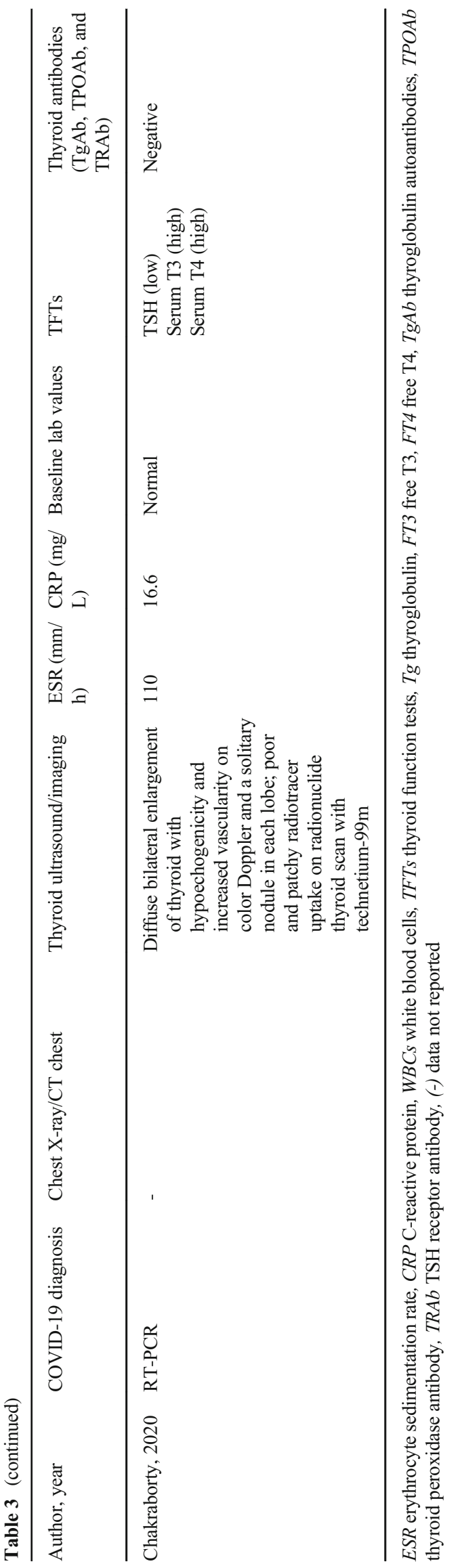

of $78.5 \pm 28.8 \mathrm{~mm} / \mathrm{h}$. Eighteen cases reported CRP (C-reactive protein) values, and it was elevated in all 18 (100\%), with an average $39.0 \pm 30.3 \mathrm{mg} / \mathrm{L}$. Deranged TFTs (thyroid function tests) were seen in all patients, with each case having low TSH, and either high T3 or high T4 or both. Serum thyroglobulin was detectable in only 3 patients. Antithyroid antibodies were only reported positive in 2 patients, one being TPO-Ab (thyroid peroxidase antibody) and the other one being $\mathrm{TgAb}$ (thyroglobulin antibodies). All 21 cases (100\%) had abnormal thyroid ultrasounds suggestive of SAT.

Twenty case reports discussed the medications of their patients; 18 out of these were administered steroids while others were given hydroxychloroquine, ibuprofen, methimazole, or only oral aspirin. Four of these were also given beta-blockers for controlling hyperthyroid symptoms. All patients recovered a few days after treatment; however, 5 patients were reported to have developed hypothyroid features/TFTs on follow-up after resolution of SAT symptoms.

\section{Discussion}

To our knowledge, this is the first systematic review of subacute thyroiditis (SAT) in COVID-19 patients. The term thyroiditis literally means thyroid inflammation. Most thyroidologists classify thyroiditis into (a) infectious thyroiditis (includes all forms of infection, except viral); (b) subacute thyroiditis; (c) autoimmune thyroiditis (Hashimoto's thyroiditis and Grave's disease); and (d) Riedel's thyroiditis [3]. Among all types of thyroiditis, subacute thyroiditis has been most strongly linked to viral infections in the literature [3]. The viral particles presumed to be of influenza or mumps were first demonstrated in the follicular epithelium of a patient suffering from subacute thyroiditis [19], and multiple viruses have been implicated as a trigger for subacute thyroiditis since then. Some of them include mumps, measles, rubella, influenza, coxsackie, adenovirus, varicella zoster virus, cytomegalovirus, Epstein-Barr virus, hepatitis E, and HIV [2, 3, 20]. In most patients, a typical viral prodrome of malaise, myalgias and fatigue is also seen clinically. [21] A variety of case reports and case series have emerged over the last year suggesting that COVID-19 virus may also act as a possible trigger for SAT, either during the infection or after its resolution. While large-scale clinical data needs to be reviewed before making strong comments, the recurring and consistent evidence from the recognition of this virus to date suggests that COVID-19 may be another virus that merits the list of viral culprits in subacute thyroiditis.

SAT typically presents as pain localized to the anterior of the neck that may radiate up to the jaw or ear on either side, low-grade fever, fatigue, and mild thyrotoxic/hyperthyroid symptoms [2, 22-26]. Tenderness on palpation and enlarged size of the gland are some of the cardinal signs. Laboratory 


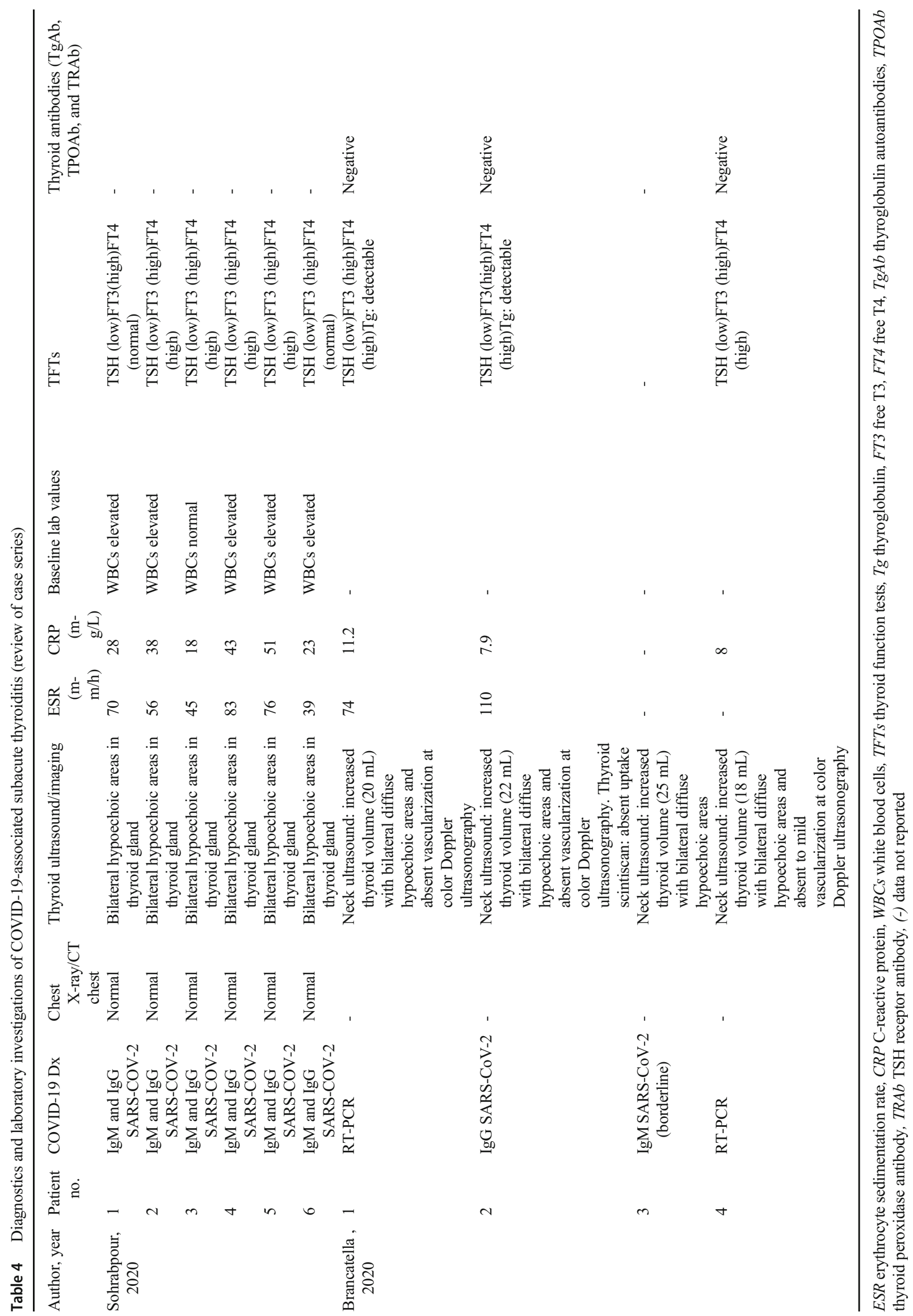


findings suggest hyperthyroid etiology (suppressed TSH, low free T4, and poor or no thyroid uptake), and thyroid ultrasound shows characteristic findings of poorly defined hypoechoic areas with a heterogeneous echo pattern [27-29]. Inflammatory markers like ESR and CRP are typically elevated. The disease may have a triphasic clinical course of hyperthyroidism, hypothyroidism, and return to normal thyroid function. The hypothyroid phase, however, may last for months until the patient becomes euthyroid [24-26]. Most of the cases we reviewed presented with findings consistent with the above mentioned clinical features and investigations. Majority of the patients presented with complaints of anterior neck pain and fever, while some patients also presented with generalized fatigue, sore throat, cough, and odynophagia. In a total sample of 21,16 patients $(76 \%)$ gave a positive history of a previous COVID-19 infection confirmed either by a previous RT-PCR or a positive antibody test (IgM/IgG). The remaining 24\% developed SAT during ongoing COVID-19 infection; however, two patients [5, 12] had an asymptomatic infection which was only confirmed via RT-PCR after they presented with SAT features.

It is believed that SARS-CoV-2 can affect the thyroid function in multiple ways. The three reported effects of the virus are (a) thyrotoxicosis (either subacute/painful thyroiditis or painless/atypical thyroiditis); (b) hypothyroidism (central or primary); and (c) nonthyroidal illness syndrome (previously known as euthyroid sick syndrome) [4]. This suggests that the effects of the virus on thyroid gland are highly variable and it is difficult to predict the abnormalities in thyroid function tests (TFTs). However, when studying the complication of subacute thyroiditis in COVID-19 alone, a strikingly similar pattern in terms of presentation, TFTs and outcome is observed.

Cytokine storm syndrome - a term used to describe the detrimental effects of hypercytokinemia on human cells - has been well described in the literature as the cause of thyroid problems [30]. While it is well documented that this storm is the cause of nonthyroidal illness syndrome seen in COVID-19 patients, at present there is little evidence to suggest the direct thyroid cytotoxic effect of cytokines, at least in humans [30, 31]. Immunemediated post-viral inflammatory reaction, involving both the adaptive and innate immune systems, has also been described in the literature as a cause of thyroid problems [32, 33]. This mechanism might be responsible for the post-infection SAT observed in the majority of patients described here too.

Among the many possible mechanisms, direct viral damage remains the most reliable evidence to date. The molecular interaction of SARS-CoV-2 with ACE-2 and TMPRSS2 receptor is required for entry into the human cells [34-36] and recent work by Rotondi et al. and Lazartigues et al. demonstrated the presence of ACE- 2 and TMPRSS2 mRNA in thyroid cells $[37,38]$. This receptor-virus interaction is similar to previously described viruses of the same family, SARS-CoV and MERS-CoV $[39,40]$. The abundance of these receptors in thyroid [41] compared to other tissues (small intestine, heart, adipose) potentially explains the subacute thyroiditis associated with SARS-CoV-2, hence strengthening the documented mechanism of direct viral injury in SAT. Moreover, the structural proximity of the virus-laden superior airway to the thyroid gland may play some role as well [42]. This mechanism - direct follicular cell damage leading to spillage of thyroid hormones into plasma - probably explains the predominant thyrotoxic clinical picture (palpitations, tachycardia, insomnia, anxiety, etc.) in more than $3 / 4$ and thyroid function tests suggesting hyperthyroid etiology in $100 \%$ of the cases. It has also been hypothesized that drugs used in COVID-19, especially glucocorticoids and low molecular weight heparin, may also damage the gland and affect thyroid function [43]. While this mechanism might play a role in thyroid abnormalities, there is not enough evidence to support it in our review because not all patients described here received steroids and heparin for COVID-19 infection.

In the cases we reviewed, more than $3 / 4$ patients $(76 \%$ ) patients were females as is seen in most cases of subacute thyroiditis. The female preponderance also highlights the autoimmune etiology of SAT that is well documented in the literature $[2,44,45]$. It is important to realize that patients can either present with pre-dominant COVID-19 features (headache, anosmia, upper respiratory symptoms) or pre-dominant SAT features (given above). After a careful review of the literature, the authors reiterate that anterior neck pain must carefully be assessed through a good history and examination so that it is not conflated with upper respiratory symptoms.

Keeping in view the above discussion, we believe it is important for clinicians to assess for SAT when encountering patients with ongoing or previous COVID-19. It is also imperative to assess for an underlying asymptomatic infection via $\mathrm{RT}$-PCR if a patient presents with features suggestive of SAT. A proper follow-up of COVID-19 might also be needed because most cases have been reported in those with a recent or previous infection. It must also be noted that treatment outcomes in all the 21 cases were excellent with steroids and anti-inflammatory drugs, reiterating the need for timely diagnosis of this clinical entity.

The authors would like to acknowledge some limitations while drawing inferences in this review. Firstly, the sample size is small because of lack of published literature on the topic. Secondly, the lack of control group and individualcentered data limits the generalizability of results. Lastly, there is a tendency towards publication bias as clinically challenging cases are more likely to be reported and published.

\section{Conclusion}

Direct viral injury and post-viral inflammatory reaction may contribute to subacute thyroiditis seen during or after COVID- 
19 infection. The mechanism of direct viral injury is well supported by the presence of ACE-2 and TMPRSS2 mRNA in thyroid cells, while post-viral inflammatory reaction has been documented previously as the cause in many other viral infections associated with subacute thyroiditis. COVID-19associated SAT is likely to present with the classic clinical features of fever and neck pain, hyperthyroid TFTs (low $\mathrm{TSH}$, high free T4), and suggestive ultrasound findings. The recognition of this clinical entity is important for physicians to consider because prompt treatment is likely to lead to complete resolution; however, the possibility of a hypothyroid phase after SAT treatment should not be ignored. A proper follow-up after COVID-19 resolution is necessary because cases of SAT have been reported months after the infection.

\section{Code Availability Not applicable.}

Authors' Contributions Muhammad Aemaz Ur Rehman: Conceptualization, literature search, critical appraisal, drafting the manuscript, proofreading, and revising the final version.

Hareem Farooq: Generating and filling tables in Microsoft Excel, analyzing results using Excel, drafting the manuscript, proofreading, and revising the final version.

Muhammad Mohsin Ali: Refining the article design, critical revision and supervision of the work, critical appraisal, proofreading, and revising the final version.

Muhammad Ebaad Ur Rehman: Collecting data according to PRISMA and designing PRISMA flowchart, revising the work critically, proofreading, and revising the final version.

Qudsia Anwar Dar: Refining the article design, critical revision of the work, and proofreading the final manuscript.

Awab Hussain: Refining article design, critical revision of the work, final approval of the manuscript.

Data availability All data analyzed during this study are included in the manuscript.

\section{Declarations}

Ethics approval Not applicable.

Consent to participate Not applicable.

Consent for publication Not applicable.

Competing interests The authors declare no competing interests.

\section{References}

1. Hennessey Jv. Subacute thyroiditis. Endotext [Internet]. 2018.

2. Shrestha RT, Hennessey J. Acute and Subacute, and Riedel's Thyroiditis. 2015 Dec 8. In: Feingold KR, Anawalt B, Boyce A, Chrousos G, de Herder WW, Dhatariya K, Dungan K, Grossman A, Hershman JM, Hofland J, Kalra S, Kaltsas G, Koch C, Kopp P, Korbonits M, Kovacs CS, Kuohung W, Laferrère B, McGee EA, McLachlan R, Morley JE, New M, Purnell J, Sahay R, Singer F, Stratakis CA, Trence DL, Wilson DP, editors. Endotext [Internet].
South Dartmouth (MA): MDText.com, Inc.; 2000-. PMID: 25905408.

3. Desailloud R, Hober D. Viruses and thyroiditis: an update. Virol J. 2009;6(1):1-14. https://doi.org/10.1186/1743-422X-6-5.

4. Scappaticcio L, Pitoia F, Esposito K, Piccardo A, Trimboli P. Impact of COVID-19 on the thyroid gland: an update. Reviews in Endocrine and Metabolic Disorders. 2020 Nov 25:1-3.https://doi. org/10.1007/s11154-020-09615-Z

5. Asfuroglu Kalkan E, Ates I. A case of subacute thyroiditis associated with Covid-19 infection. J Endocrinol Investig. 2020;43: 1173-4. https://doi.org/10.1007/s40618-020-01316-3.

6. Brancatella A, Ricci D, Cappellani D, Viola N, Sgrò D, Santini F, et al. Is subacute thyroiditis an underestimated manifestation of SARS-CoV-2 infection? Insights from a case series. The Journal of Clinical Endocrinology \& Metabolism. 2020;105(10):e3742-e6. https://doi.org/10.1210/clinem/dgaa537.

7. Campos-Barrera E, Alvarez-Cisneros T, Davalos-Fuentes M. Subacute thyroiditis associated with COVID-19. Case reports in endocrinology. 2020;2020:1-4. https://doi.org/10.1155/2020/ 8891539.

8. Chakraborty U, Ghosh S, Chandra A, Ray AK. Subacute thyroiditis as a presenting manifestation of COVID-19: a report of an exceedingly rare clinical entity. BMJ Case Reports CP. 2020;13(12): e239953. https://doi.org/10.1136/bcr-2020-239953.

9. Guven M. Subacute thyroiditis in the course of coronavirus disease 2019: A Case Report. Journal of Endocrinology and Metabolism. 2020;10(3-4):110-2. https://doi.org/10.14740/jem678.

10. Ippolito S, Dentali F, Tanda M. SARS-CoV-2: a potential trigger for subacute thyroiditis? Insights from a case report. J Endocrinol Investig. 2020;43:1171-2. https://doi.org/10.1007/s40618-02001312-7.

11. Khatri A, Charlap E, Kim A. Subacute thyroiditis from COVID-19 infection: a case report and review of literature. European Thyroid Journal. 2020;9(6):309-13.10.1159/000511872.

12. Maris J, Florencio MQV, Joven MH. Subacute thyroiditis in a patient with coronavirus disease 2019. AACE clinical case reports. 2020;6(6):e361-e4. https://doi.org/10.4158/ACCR-2020-0524.

13. Mattar SAM, Koh SJQ, Chandran SR, Cherng BPZ. Subacute thyroiditis associated with COVID-19. BMJ Case Reports CP. 2020;13(8):e237336. https://doi.org/10.1136/bcr-2020-237336.

14. Ruggeri RM, Campennì A, Siracusa M, Frazzetto G, Gullo D. Subacute thyroiditis in a patient infected with SARS-COV-2: an endocrine complication linked to the COVID-19 pandemic. Hormones. 2020;20:1-3. https://doi.org/10.1007/s42000-02000230-w.

15. Chong WH, Shkolnik B, Saha B, Beegle S. Subacute thyroiditis in the setting of coronavirus disease 2019. Am J Med Sci. 2020;361: 400-2. https://doi.org/10.1016/j.amjms.2020.09.011.

16. Brancatella A, Ricci D, Viola N, Sgrò D, Santini F, Latrofa F. Subacute thyroiditis after SARS-CoV-2 infection. J Clin Endocrinol Metab. 2020;105(7):2367-70. https://doi.org/10.1210/ clinem/dgaa276.

17. Sohrabpour S, Heidari F, Karimi E, Ansari R, Tajdini A, Heidari F. Subacute thyroiditis in COVID-19 patients. Eur Thyroid J. 2020;9(6):322-4.10.1159/000511707.

18. Moola S, Munn Z, Tufanaru C, Aromataris E, Sears K, Sfetcu R, Currie M, Lisy K, Qureshi R, Mattis P, Mu P. Chapter 7: Systematic reviews of etiology and risk. In: Aromataris E, Munn Z (Editors). JBI Manual for Evidence Synthesis. JBI, 2020. Available from https://synthesismanual.jbi.global. https://doi.org/10.46658/ JBIMES-20-08

19. Satoh M. Virus-like particles in the follicular epithelium of the thyroid from a patient with subacute thyroiditis (DE QUERVAIN). Pathol Int. 1975 Jul;25(4):499-501. https://doi.org/ 10.1111/j.1440-1827.1975.tb00868.x. 
20. Prummel MF, Strieder T, Wiersinga WM. The environment and autoimmune thyroid diseases. Eur J Endocrinol. 2004;150(5): 605-18. https://doi.org/10.1530/eje.0.1500605.

21. Nishihara E, Ohye H, Amino N, Takata K, Arishima T, Kudo T, et al. Clinical characteristics of 852 patients with subacute thyroiditis before treatment. Intern Med. 2008;47(8):725-9. https://doi.org/ 10.2169/internalmedicine.47.0740.

22. Volpé R. 7 Subacute (de Quervain's) thyroiditis. Clin Endocrinol Metab. 1979;8(1):81-95. https://doi.org/10.1016/S0300-595X(79) 80011-0.

23. Walfish PG. Thyroiditis. Curr Ther Endocrinol Metab. 1997;6: 117-22.

24. Intenzo CM, Park CH, Kim SM, Capuzzi DM, Cohen SN, Green PA. Clinical, laboratory, and scintigraphic manifestations of subacute and chronic thyroiditis. Clin Nucl Med. 1993;18(4):302-6. https://doi.org/10.1097/00003072-199304000-00007.

25. Singer PA. Thyroiditis: acute, subacute, and chronic. Med Clin N Am. 1991;75(1):61-77. https://doi.org/10.1016/s0025-7125(16) 30472-2.

26. Alfadda AA, Sallam RM, Elawad GE, AlDhukair H, Alyahya MM. Subacute thyroiditis: clinical presentation and long term outcome. Int J Endocrinol. 2014;2014. https://doi.org/10.1155/2014/794943.

27. Ruchala M, Szczepanek-Parulska E, Zybek A, Moczko J, Czarnywojtek A, Kaminski G, et al. The role of sonoelastography in acute, subacute and chronic thyroiditis: a novel application of the method. Eur J Endocrinol. 2012;166(3):425-32. https://doi.org/10. 1530/eje-11-0736.

28. Frates MC, Marqusee E, Benson CB, Alexander EK. Subacute granulomatous (de Quervain) thyroiditis: grayscale and color Doppler sonographic characteristics. J Ultrasound Med. 2013;32(3):505-11. https://doi.org/10.7863/jum.2013.32.3.505.

29. Park SY, Kim EK, Kim MJ, Kim BM, Oh KK, Hong SW, et al. Ultrasonographic characteristics of subacute granulomatous thyroiditis. Korean J Radiol. 2006;7(4):229. https://doi.org/10.3348/ kjr.2006.7.4.229.

30. Croce L, Gangemi D, Ancona G, Liboà F, Bendotti G, Minelli L, et al. The cytokine storm and thyroid hormone changes in COVID19. J Endocrinol Investig. 2021;9:1-4. https://doi.org/10.1007/ s40618-021-01506-7.

31. Wang W, Su X, Ding Y, Fan W, Zhou W, Su J, et al. Thyroid function abnormalities in COVID-19 patients. Front Endocrinol. 2020;11. https://doi.org/10.3389/fendo.2020.623792.

32. Wei L, Sun S, Xu C-h, Zhang J, Xu Y, Zhu H, et al. Pathology of the thyroid in severe acute respiratory syndrome. Hum Pathol. 2007;38(1):95-102. https://doi.org/10.1016/j.humpath.2006.06. 011.

33. Tang Y, Liu J, Zhang D, Xu Z, Ji J, Wen C. Cytokine storm in COVID-19: the current evidence and treatment strategies. Front Immunol. 2020;11:1708. https://doi.org/10.3389/fimmu.2020. 01708 .
34. Wang Q, Zhang Y, Wu L, Niu S, Song C, Zhang Z, et al. Structural and functional basis of SARS-CoV-2 entry by using human ACE2. Cell. 2020;181(4):894-904. e9. https://doi.org/10.1016/j.cell.2020. 03.045 .

35. Hoffmann M, Kleine-Weber H, Schroeder S, Krüger N, Herrler T, Erichsen S, et al. SARS-CoV-2 cell entry depends on ACE2 and TMPRSS2 and is blocked by a clinically proven protease inhibitor. Cell. 2020;181(2):271-80. e8. https://doi.org/10.1016/j.cell.2020. 02.052 .

36. Kuba K, Imai Y, Rao S, Gao H, Guo F, Guan B, et al. A crucial role of angiotensin converting enzyme 2 (ACE2) in SARS coronavirusinduced lung injury. Nat Med. 2005;11(8):875-9. https://doi.org/ $10.1038 / \mathrm{nm} 1267$.

37. Rotondi M, Coperchini F, Ricci G, Denegri M, Croce L, Ngnitejeu $\mathrm{S}$, et al. Detection of SARS-COV-2 receptor ACE-2 mRNA in thyroid cells: a clue for COVID-19-related subacute thyroiditis. Journal of endocrinological investigation. 2020:1-6.https://doi.org/ 10.1007/s40618-020-01436-w

38. Lazartigues E, Qadir MMF, Mauvais-Jarvis F. Endocrine significance of SARS-CoV-2's reliance on ACE2. Endocrinology. 2020;161(9):bqaa108. https://doi.org/10.1210/endocr/bqaa108.

39. Li W, Moore MJ, Vasilieva N, Sui J, Wong SK, Berne MA, et al. Angiotensin-converting enzyme 2 is a functional receptor for the SARS coronavirus. Nature. 2003;426(6965):450-4. https://doi.org/ 10.1038 /nature 02145 .

40. Turner AJ, Tipnis SR, Guy JL, Rice GI, Hooper NM. ACEH/ACE2 is a novel mammalian metallocarboxypeptidase and a homologue of angiotensin-converting enzyme insensitive to ACE inhibitors. Can J Physiol Pharmacol. 2002;80(4):346-53. https://doi.org/10. 1139/y02-021.

41. Li M-Y, Li L, Zhang Y, Wang X-S. Expression of the SARS-CoV2 cell receptor gene ACE2 in a wide variety of human tissues. Infectious diseases of poverty. 2020;9:1-7. https://doi.org/10. 1186/s40249-020-00662-x.

42. Bellastella G, Maiorino MI, Esposito K. Endocrine complications of COVID-19: what happens to the thyroid and adrenal glands? J Endocrinol Investig. 2020;43:1169-70. https://doi.org/10.1007/ s40618-020-01311-8.

43. Chen W, Tian Y, Li Z, Zhu J, Wei T, Lei J. Potential interaction between SARS-CoV-2 and thyroid: a review. Endocrinology. 2021. https://doi.org/10.1210/endocr/bqab004.

44. Lazarus JH. Silent thyroiditis and subacute thyroiditis. Werner and Ingbar's The Thyroid-A Fundamental and Clinical Text. 1996:57791.

45. Bindra A, Braunstein GD. Thyroiditis. Am Fam Physician. 2006;73(10):1769-76.

Publisher's Note Springer Nature remains neutral with regard to jurisdictional claims in published maps and institutional affiliations. 